\title{
An ATP-dependent inhibitor of TBP binding to DNA
}

\author{
David T. Auble and Steven Hahn \\ Fred Hutchinson Cancer Research Center, Seattle, Washington 98104 USA
}

\begin{abstract}
An activity in yeast nuclear extracts (termed ADI) is described that inhibits the binding of the TATA-binding protein (TBP) to DNA in an ATP-dependent manner. The effect is reversible, ATP specific, rapid, and is not promoter specific. ADI is specific for TBP because three other protein-DNA complexes are not affected by ADI. The action of ADI is blocked by association of TFIIA with the TBP-DNA complex. ADI activity at the adenovirus major late promoter requires a segment of DNA upstream from the TATA sequence, suggesting that ADI recognizes aspects of both TBP and DNA. The evolutionarily conserved carboxy-terminal domain of TBP is sufficient for ADI recognition, and amino acids in the basic region of TBP are required for ADI action. ADI can repress transcription in vitro in an ATP-dependent manner. In the presence of ADI, both TFIIA and TBP are required to commit a template to transcription. A model of ADI action is proposed, and possible roles of $\mathrm{ADI}$ in the regulation of the transcription complex assembly are discussed.
\end{abstract}

[Key Words: Transcription; TBP; ADI; yeast; inhibitor; ATP]

Received December 22, 1992; revised version accepted January 23, 1993.

The formation of a transcription complex capable of initiating the synthesis of mRNA requires several factors in addition to RNA polymerase II. These general factors include TFIIA, TFIIB, TFIID, TFIIE, TFIIF, TFIIH, and TFII) (Sawadogo and Sentenac 1990; Cortes et al. 1992; Fischer 1992; Gileadi et al. 1992; Lu et al. 1992; Zawel and Reinberg 1992). For many genes, the first step in transcription complex formation is thought to involve the binding of TFIID to a TATA element located upstream of the start site of transcription (Davison et al. 1983, Van Dyke et al. 1988; Buratowski et al. 1989; Cortes et al. 1992). In mammalian cells, TFIID appears to consist of a TATA-binding protein (TBP) tightly complexed to a number of other polypeptides, at least some of which are required for activated transcription in vitro (Tanese et al. 1991 and references therein; Zhou et al. 1992). The gene encoding TBP has been cloned from several organisms (for review, see Greenblatt 1991), and the crystal structure of TBP has been determined (Nikolov et al. 1992). In yeast, the TFIID fraction contains a monomeric TBP of $\sim 27 \mathrm{kD}$, which does not appear to be tightly complexed to other proteins.

The binding of yeast TBP is relatively slow, but once it occurs the TBP-DNA interaction is stable / Hahn et al. $1989 \mathrm{a}$ ), and this interaction is thought to commit a template to transcription (Buratowski et al. 1989). Therefore, the binding of TBP to DNA is likely a point at which transcription complex assembly is regulated. Evidence has accumulated suggesting that some transcription factors exert their positive effects either directly or indirectly by interaction with TFIID (Sawadogo and Roeder 1985b; Abmayr et al. 1988; Horikoshi et al. 1988a,b, 1991; Pugh and Tjian 1990; Stringer et al. 1990; Lee et al.
1991), although other steps in complex assembly have been proposed as targets (Lin et al. 1991). Here, we describe the characterization and partial purification of a novel ATP-dependent inhibitor of TBP binding (ADI) to DNA. $\bar{A} D I$ is specific for TBP and can be antagonized by other general transcription factors that form higher order complexes with TBP and DNA. As a result, ADI is a good candidate for a cellular activity that regulates transcription complex assembly by modulating the binding of TBP to DNA.

Results

Assay of $A D I$

$\mathrm{ADI}$ was discovered during the initial purification and characterization of yeast TBP. After purification of yeast TBP by heparin and DEAE chromatography (Buratowski et al. 1988), it was observed that this crude TBP fraction gave a weak DNase I footprint at the adenovirus major late promoter TATA element. In an attempt to improve the DNase I footprinting activity, a number of conditions in the binding reaction were varied, including the addition of ATP. Unexpectedly, ATP was found to completely inhibit the binding of TBP. As demonstrated below, this inhibition was the result of an ADI. Inhibition of TBP binding was used as an assay to purify and characterize this factor.

For subsequent studies we have employed a homogeneous preparation of yeast TBP made in Escherichia coli (Reddy and Hahn 1991) and a partially purified preparation of ADI that is free of TBP, TFIIA, and TFIIB (Table 1; Bio-Rex 70 fraction). The ADI in this Bio-Rex 70 fraction 
Table 1. Purification of ADI

\begin{tabular}{lccc}
\hline & $\begin{array}{l}\text { Total } \\
\text { protein } \\
(\mathrm{mg})\end{array}$ & $\begin{array}{l}\text { Total } \\
\text { units }^{\mathrm{a}}\end{array}$ & $\begin{array}{l}\text { Specific } \\
\text { activity } \\
\text { (U/mg) }\end{array}$ \\
\hline Ntep & 735.0 & - & - \\
NeAclear extract & 190.4 & - & - \\
Phenyl-Sepharose & 16.0 & 55,000 & $3,437.5$ \\
Bio-Rex 70 & 0.72 & 24,000 & $33,333.0$ \\
\hline ane unit of ADI activity is defined as the amount required to \\
completely dissociate all of the TBP-DNA complexes detected \\
in a standard gel shift assay performed as described in Materials \\
and methods.
\end{tabular}

is estimated to be $\sim 1000$-fold enriched from yeast cells (see Materials and methods). ADI can readily be detected in a gel shift assay. Several basic features of ADI are illustrated in the gel shift assay shown in Figure 1A. When $\mathrm{ADI}$ is added to a TBP-DNA-binding reaction in the absence of ATP, a small fraction of the TBP-DNA complex is shifted to a slower migrating complex (TBPADI-DNA) that depends on both TBP and the ADI fraction (Fig. 1A, cf. lanes 1 and 2). This slower mobility complex is not formed stoichiometrically with TBP on the adenovirus major late promoter under these incubation conditions, but it is reproducibly detected (also see Figs. 2 and $3 \mathrm{C}$, below). The supershifted complex is detected more easily using the LEU2 TATA element as a probe (see below). We speculate that this complex results from the binding of ADI to the TBP-DNA complex, and evidence in support of this point is detailed below.

In the presence of ADI and $5 \mu \mathrm{M}$ ATP, the TBP-DNA complex is eliminated almost completely (Fig. 1A, lanes 3,9 ). The ADI fraction is required for this activity, as the addition of ATP to TBP alone has no effect on the TBPDNA complex (lane 5). ADI may require ATP hydrolysis because the nonhydrolyzable ATP analog AMP-PNP does not substitute for ATP in this reaction (lane 4). Other ATP analogs, such as ATP- $\gamma$-S, and $\alpha, \beta$ - and $\beta, \gamma-$ methyleneadenosine $5^{\prime}$-triphosphate, also fail to substitute for ATP in this reaction (not shown). ADI alone has no specific DNA-binding activity (Fig. 1A, lane 8, and B). A small amount of a complex that migrates faster than the TBP-DNA complex is also detected in reactions that contain ADI \{lanes 2-4, 8-11\}. This complex does not require the presence of TBP (lane 8); it is only formed on the major late promoter and not the LEU2 promoter (lanes 12-14; see below), and the peak of this binding activity does not coincide exactly with the peak of ADI activity (not shown) so it appears to be unrelated to ADI.

$\mathrm{ADI}$ does not alter or destroy TBP irreversibly because the ATP-dependent effect can be reversed with bacterial alkaline phosphatase (lane 10). The effect of the phosphatase preparation is specific for the phosphatase enzyme itself, as inhibition of phosphatase with $\beta$-glycerophosphate reverses the effect of phosphatase and allows ADI to function (lane 11). The phosphatase is capable of removing phosphate from ATP, as well as from proteins and DNA, and the $K_{\mathrm{m}}$ of the phosphatase for ATP is apparently quite low. Preincubation of phosphatase and ATP in the binding reaction results in depletion of ATP; consequently, ADI does not function (not shown). This, plus the fact that TBP is not phosphorylated by ADI (see below), indicates that the ability of the phosphatase to reverse the inhibitory effect is the result of its ATPase activity.

The $K_{\mathrm{m}}$ for ATP in this reaction is $\sim 1 \mu \mathrm{M}$, and the effect of ATP is rapid and stable; the result of adding ATP for 1 or $5 \mathrm{~min}$ is very similar to adding ATP during the entire 25-min incubation (Fig. 1A, cf. lanes 3 and 9; data not shown). ADI is not promoter specific because complexes formed on either the major late promoter (lanes 1-11) or the yeast LEU2 TATA element (lanes 12-14) are equally dissociated by ADI. Note that the TBP-ADI-DNA complex is detected more easily on the LEU2 TATA element than on the major late promoter (cf. lanes 2 and 13 ) but that ADI dissociates TBP bound to either template in the presence of ATP (lanes 3,14). ADI was also found to form ternary complexes, with TBP bound to the CYCl, HIS4, and DEDl promoters, and complexes formed on all of these templates were dissociated by ATP (not shown).

To rule out that the effect of ADI was specific to the gel shift assay, the effects of ADI were confirmed in DNase I footprinting experiments (Fig. 1B). Purified recombinant yeast TBP was found to protect bases from nuclease digestion at positions -18 to -37 , in agreement with previous results (Hahn et al. 1989c). The ADI fraction alone results in no detectable protection of DNA from DNase I digestion; cleavage is enhanced at -9 and -10 , but these changes are not affected by TBP or ATP. In the absence of ATP, ADI causes slight changes in the DNase I footprint of TBP. In particular, the addition of ADI protects positions -38 and -39 from DNase I digestion, a result discussed more fully below. In the presence of ATP, the TBP footprint largely disappears, indicating that TBP has been displaced from the TATA box.

\section{ADI recognizes the conserved domain of $T B P$}

The effect of ADI on complexes formed between DNA and a 185-amino-acid carboxy-terminal fragment of TBP $(\triangle \mathrm{TBP})$ was tested. This truncated protein contains all essential TBP function in yeast (Cormack et al. 1991; Reddy and Hahn 1991). Incubation of $\triangle$ TBP with ADIcontaining Bio-Rex 70 fractions in the absence of ATP results in the appearance of a supershifted band /Fig. 2, $\triangle T B P-A D I)$. In fractions 25 and 26, the $\triangle$ TBP-DNA complex has been supershifted almost completely to the upper complex, whereas only a portion of the $\triangle T B P-$ DNA complex has been supershifted in fractions 27 and 28. In the presence of ATP, the supershifted material is eliminated completely, as is the small amount of $\triangle T B P$ DNA complex that was present in reactions with fractions 25 and 26 . Thus, the quantity of supershifted complex parallels the elution profile of ADI activity, and this suggests that $\triangle T B P$ is capable of quantitatively forming a ternary complex with DNA and ADI in the absence of ATP. 


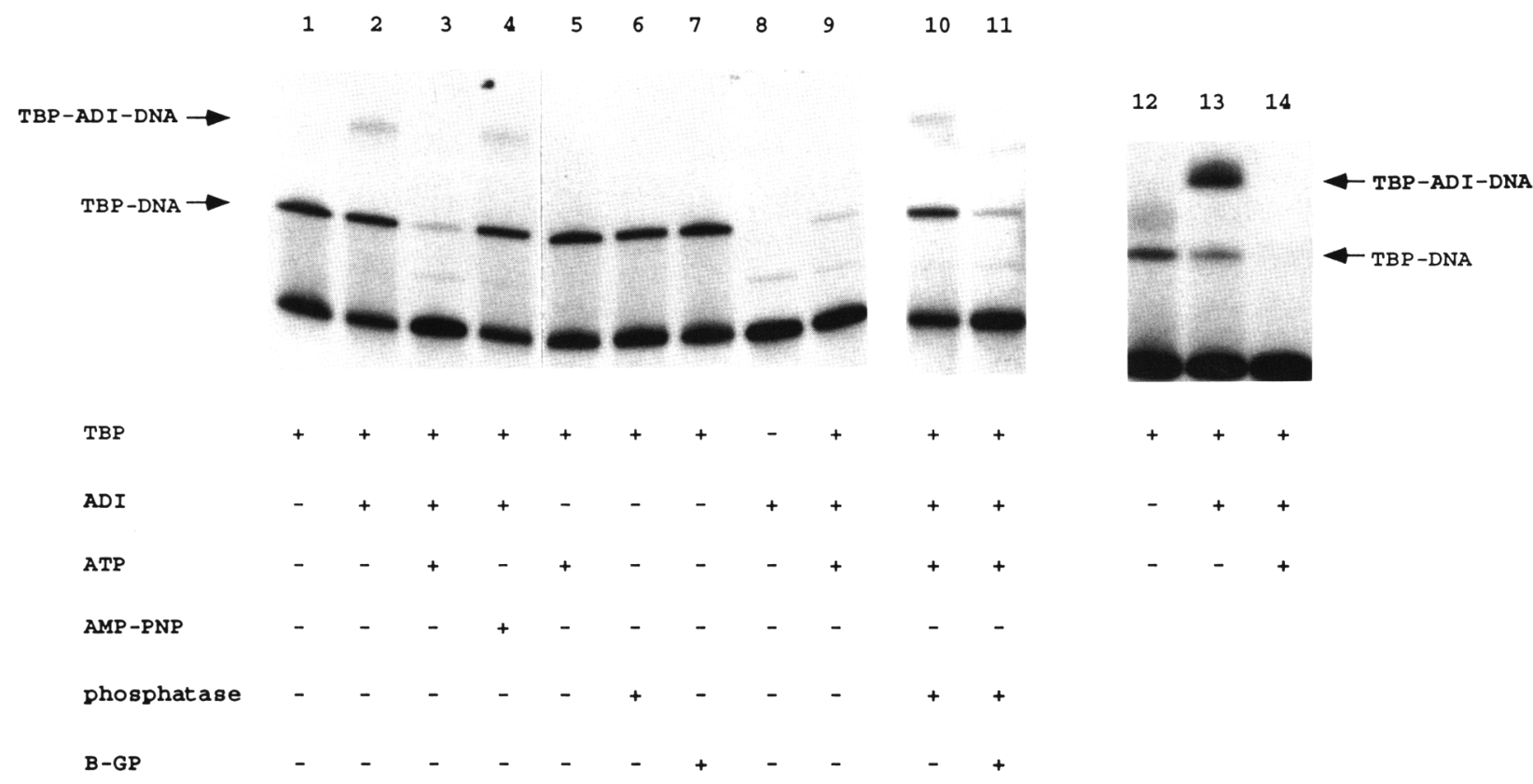

Figure 1. ATP dependent inhibition of TBP binding to DNA. (A) A radiolabeled fragment of DNA spanning the adenovinus major late promoter TATA sequence (lanes 1-11) or the LEU2 TATA sequence (lanes 12-14) was incubated with purified recombinant yeast TBP and/or ADI (where indicated), and the TBP-DNA complex was then resolved from the free DNA by nondenaturing polyacrylamide gel electrophoresis as described in Materials and methods. The TBP-DNA and TBP-ADI-DNA complexes are indicated. The reactions in lanes 1-8 and 12-14 were incubated at room temperature for $25 \mathrm{~min}_{;} 5 \mu \mathrm{M}$ ATP or the nonhydrolyzable ATP analog AMP-PNP was then added for $5 \mathrm{~min}$ where indicated. The reaction in lane 9 contained ATP during the entire $25-\mathrm{min}$ incubation. The reactions in lanes 10 and 11 were incubated for $25 \mathrm{~min}$ at room temperature, ATP was then added for $5 \mathrm{~min}$ to dissociate the TBP-DNA complexes, and bacterial alkaline phosphatase $(0.14$ units, Sigma) (lane 10$)$ or phosphatase plus $5 \mathrm{~mm} \beta$-glycerophosphate (lane 11) was then added for an additional 25-min incubation at room temperature before loading onto the gel. Reactions with ADI contained $1.0 \mu \mathrm{l}(\sim 1 \mathrm{unit})$ of the Bio-Rex fraction (see Table 1). (B) DNase I footprinting reactions were performed by partial digestion of a uniquely end-labeled adenovirus major late promoter fragment preincubated with no protein (NP), TBP alone, ADI fraction alone, TBP plus the ADI fraction (TBP + ADI), or TBP plus ADI plus $5 \mu \mathrm{M}$ ATP $(\mathrm{TBP}+\mathrm{ADI}+\mathrm{ATP})$ as described above for $A$ and in Materials and methods. The reaction products were visualized by autoradiography of a $10 \%$ polyacrylamide sequencing gel. The TBP footprint extends from approximately -18 to -37 . Note that these reactions contained 4.8-fold more TBP and 3.2-fold more ADI than was present in the reactions shown in $A$.

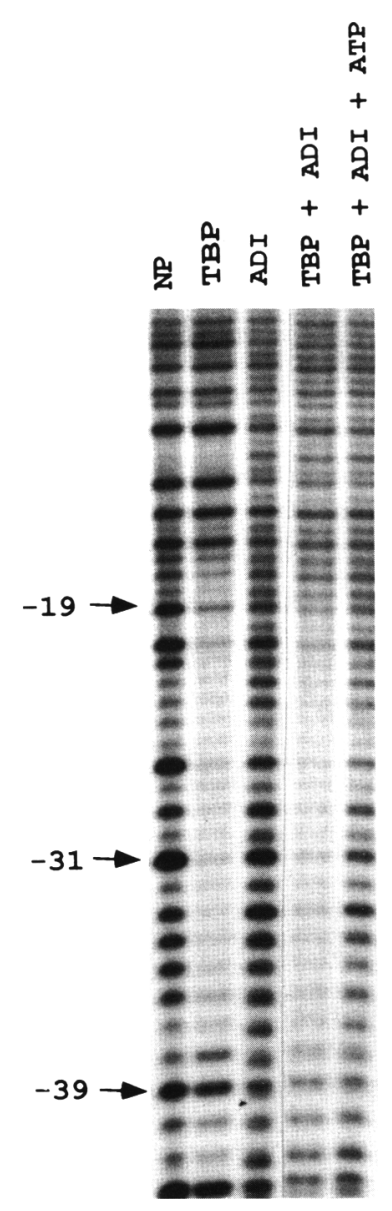



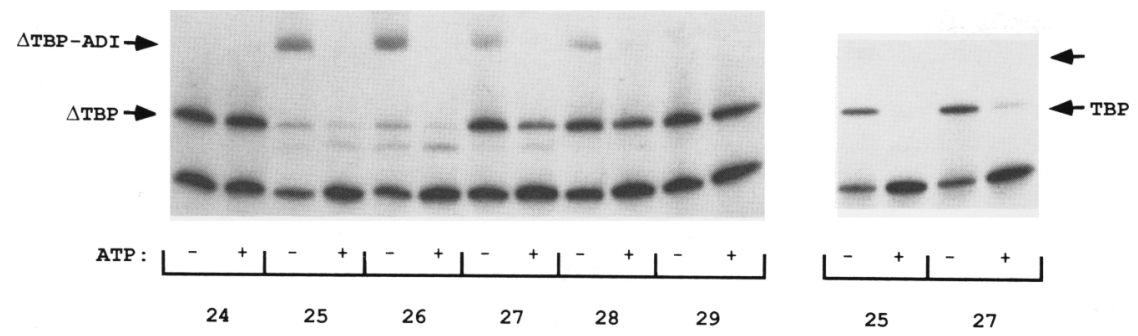

Figure 2. Effect of ADI on DNA complexes formed with the carboxy-terminal domain of TBP. Purified carboxy-terminal domain of TBP (amino acids 56-240; left) or full-length TBP (right) was incubated with radiolabeled adenovirus major late promoter DNA fragment and aliquots of fractions (24-29, as shown) across the BioRex 70 column salt gradient, which includes the peak of inhibitor activity (25-

27). ATP $(5 \mu \mathrm{M})$ was also included where indicated. The reaction products were resolved on a $6 \%$ nondenaturing polyacrylamide gel as described in Materials and methods. ADI activity cofractionates with a new complex formed in the absence of ATP ( $\triangle$ TBP-ADI), which we speculate is formed between TBP, DNA, and ADI (see Discussion). Both this ternary complex and the $\triangle T B P-D N A$ complex $(\triangle \mathrm{TBP}$, arrow $)$ are eliminated by ATP. The upper arrow (right) indicates the position of a similar very faint supershifted complex seen with full-length TBP; this is seen more easily in Fig. 1.

The right-hand panel of Figure 2 shows the results with full-length TBP and ADI fractions 25 and 27, which are very similar to results in Figure $1 \mathrm{~A}$; only a small fraction of the TBP-DNA complex is stably bound by $\mathrm{ADI}$ in the absence of ATP (marked with an arrow). Although the TBP-ADI-DNA complex was detected more readily on the LEU2 promoter than on the major late promoter, incubation of the LEU2 promoter with $\triangle T B P$ and $\mathrm{ADI}$ results in the formation of an even greater proportion of $\triangle T B P-A D I-D N A$ complexes than are formed under the same conditions using full-length TBP (not shown). Thus, ADI binds more strongly to a $\triangle T B P-D N A$ complex than the full-length TBP-DNA complex. This suggestion is supported by the observation that ADI activity can be bound to a column containing $\triangle T B P$ bound to an immobilized TATA sequence but not to a column containing full-length TBP bound to a TATA sequence (not shown). Finally, ADI activity can be squelched by the addition of excess $\triangle T B P$, but not full-length TBP, to a gel shift reaction using the major late promoter (not shown).
As both the truncated TBP-DNA complex and the ternary complex are abolished by $\mathrm{ADI}$ in the presence of ATP, the conserved carboxy-terminal core of TBP contains the features that are recognized by ADI. Consistent with these results, ADI was found to dissociate human TBP from DNA in the gel shift assay (not shown); a truncated form of human TBP has not been tested.

\section{Specificity of ADI function}

To establish the specificity of ADI action, we determined the effect of ADI on two other yeast DNA-binding complexes (Fig. 3). In gel shift assays, the binding of both purified GAL4-VP16 (Carey et al. 1990) and HAP2,3,4 proteins (Hahn and Guarente 1988; Forsburg and Guarente 1989) to their cognate DNA sequences was tested. There was no detectable effect of ADI on these complexes either in the presence or absence of ATP (Figure $3 \mathrm{~A}, \mathrm{~B} \mid$. ADI also had no effect on complexes formed between DNA and Myb, a protein whose DNA-binding activity was shown to be regulated by phosphorylation
A (GAT4-VP16)

B (HAP2, 3, 4)

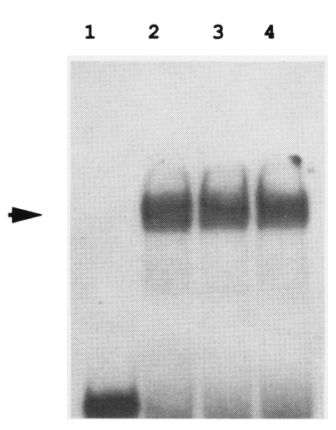

GAL4-VP16

ADI

ATP
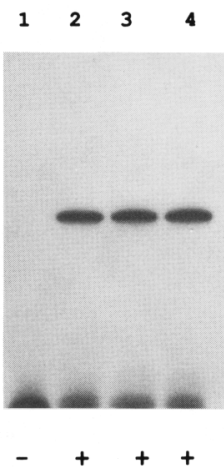

$$
-\quad++
$$$$
-\quad-\quad+
$$

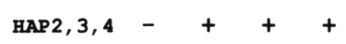

$-\quad+\quad+$
C (TBP)

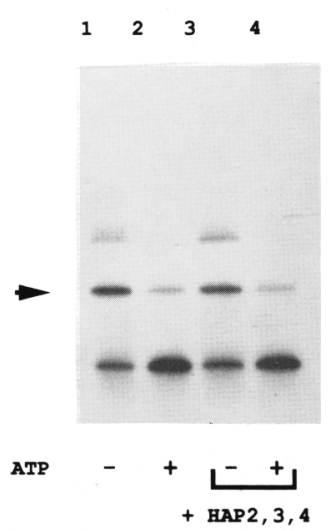

Figure 3. $A D I$ is specific for TBP-DNA complexes. (A) Gel shift analysis of GAL4-VP16 binding to a GAL4 DNAbinding site. Radiolabeled DNA was incubated with purified GAL4-VP16 for 10 min at room temperature. ADI $\{1 \mu$ l of the Bio-Rex 70 fraction) was then added in the presence or absence of $5 \mu \mathrm{M}$ ATP /as indicated, and the reactions were then loaded onto a $6 \%$ polyacrylamide gel as described in Materials and methods. (B) Gel shift analysis of the binding of yeast HAP2,3,4 proteins to a radiolabeled DNA-binding site. Purified HAP2,3,4 proteins were incubated with DNA for $30 \mathrm{~min}$ at room temperature, followed by the addition of the ADI fraction and ATP where indicated. The reaction products were resolved on a $4 \%$ polyacrylamide gel as described in Materials and methods. (C) TBP was incubated with radiolabeled adenovirus major late promoter DNA fragment for $20 \mathrm{~min}$ at room temperature as in Fig. $1 \mathrm{~A}$. The ADI fraction was then added to all reactions, and HAP2,3,4 and ATP were added where indicated for 5 min before loading onto the gel. 
(Lüscher et al. 1990; data not shown). The failure of ADI to displace HAP2,3,4 from its DNA-binding site is not the result of a contaminant in the preparation that inactivates ADI (Figure $3 \mathrm{C}$ ). ADI was found to dissociate TBP even in the presence of HAP2,3,4. Similar results were obtained in a control experiment using GAL4-VP16.

\section{Mechanism of ADI action and the role of ATP}

To determine whether TBP or proteins in the ADI fraction were covalently modified by ATP, these fractions

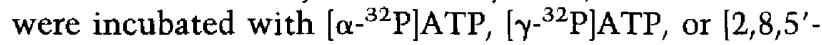
${ }^{3} \mathrm{H}$ |ATP under the same conditions as in the gel shift assay (data not shown). Neither $\left[\alpha^{-32} \mathrm{P}\right] \mathrm{ATP}$ nor $\left[{ }^{3} \mathrm{H}\right] \mathrm{ATP}$ labeled TBP or proteins in the ADI fraction. The ADI fraction appears to contain a kinase, as several polypeptides in this fraction were labeled when incubated with $\left[\gamma^{32} \mathrm{P}\right] \mathrm{ATP}$, but TBP was not labeled and the phosphorylation of other proteins does not depend on the presence of either TBP or DNA. In a separate set of experiments it was found that ADI remains ATP dependent whether or not it has been preincubated with ATP before its addition to TBP-DNA complexes (not shown). Because no polypeptides were detected that were phosphorylated in

A

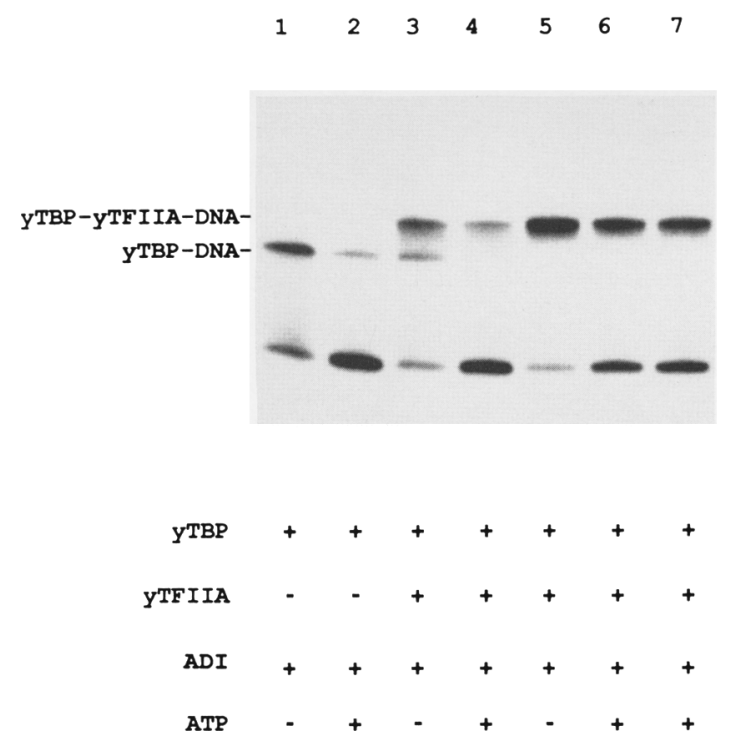

a TBP- and DNA-dependent manner, these data suggest that ADI is not a kinase. A helicase might be able to unwind DNA and thereby dissociate TBP-DNA complexes; however, DNA unwinding activity has not been detected in any of the ADI fractions (not shown).

\section{Effect of TFIIA and TFIIB on ADI action}

The ability of ADI to dissociate complexes formed between TBP, TFIIA, or TFIIB was tested. As shown in Figure $4 \mathrm{~A}$, the addition of purified recombinant yeast TFIIA to a binding reaction containing TBP results in the formation of a TBP-TFIIA-DNA complex (lanes 3-7; Ranish et al. 1992). The binding reactions were performed with either a subsaturating amount (lanes 3,4 ) or a saturating amount (lanes 5-7) of TFIIA. In the presence of either subsaturating or saturating amounts of TFIIA, ADI reduces the TBP-TFILA-DNA complex by, at most, twofold, as determined by densitometry. When both TBP-DNA and TBP-TFIIA-DNA complexes can be detected, the addition of ADI and ATP results in a sixfold reduction in the TBP-DNA complex but only a twofold reduction in the amount of the TBP-TFIIA-DNA complex (lanes 3,4$)$. Thus, TFIIA appears to stabilize TBP to

\section{B}

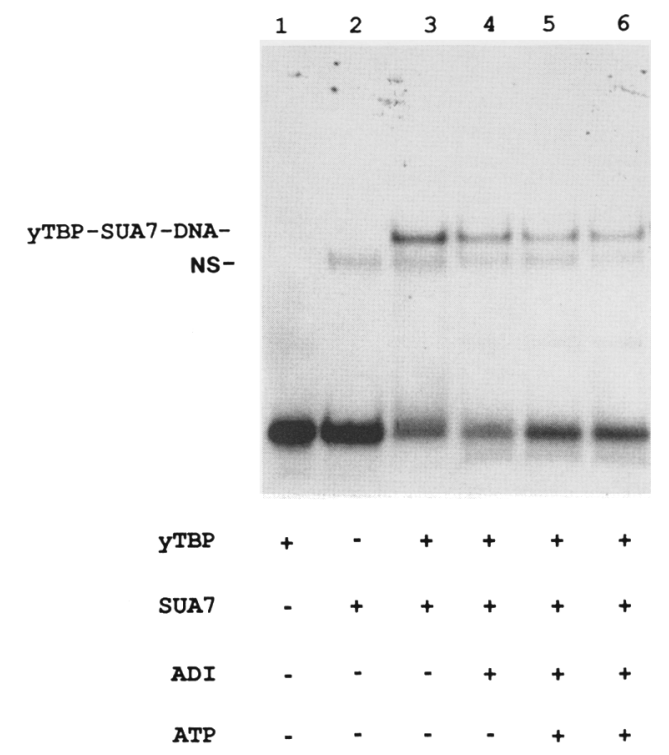

Figure 4. Effects of TFIIA and TFIIB on ADI activity. (A) In lanes 1-6 yeast TBP, yeast TFIIA, ADI and ATP were incubated as indicated with a radiolabeled adenovirus major late promoter DNA fragment for $20 \mathrm{~min}$ at room temperature. In lane 7, TBP, ADI, DNA, and ATP were incubated together for $20 \mathrm{~min}$ followed by the addition of TFIIA for $20 \mathrm{~min}$. The reactions in lanes 3 and 4 contained $\sim 0.7$ DNA-binding units of TFIIA, whereas the reactions in lanes $5-7$ contained $\sim 2$ units of TFIIA. The reaction products were analyzed by nondenaturing gel electrophoresis as described in Materials and methods. The TBP-DNA and TBP-TFIIA-DNA complexes are indicated. $(B)$ Yeast TBP, yeast TFIIB (SUA7), ADI, and ATP were incubated with radiolabeled adenovirus major late promoter DNA fragment (as above) for $30 \mathrm{~min}$ at room temperature, as indicated, and the various complexes were resolved on a $6 \%$ polyacrylamide gel as described in Materials and methods. In this gel system, neither TBP nor SUA7 alone are capable of forming a complex that is stable to gel electrophoresis. The position of the observed TBP-SUA7-DNA complex is shown. Note that a nonspecific complex (NS) is formed between DNA and a contaminant protein in the SUA7 preparation; this complex is present in all lanes that contain SUA7 (even lane 2 in which no TBP is present). 
dissociation by ADI. Surprisingly, TFIIA can also reverse the effect of ADI. When TBP and DNA are first incubated with ADI and ATP to prevent the formation of TBP-DNA complexes, the subsequent addition of TFIIA still results in the formation of TBP-TFIIA-DNA ternary complexes (cf. lanes 6 and 7).

The effects of the addition of purified recombinant SUA7 protein [yeast TFIIB (Pinto et al. 1992)] on ADI function are shown in Figure 4B. A nonspecific proteinDNA complex attributable to a contaminating polypeptide in the recombinant SUA7 preparation is observed when SUA7 alone is added (Fig. 4B, NS). Under the gel conditions used, interactions between DNA and either SUA7 or TBP cannot be detected (lanes 1,2) (Maldonado et al. 1990). The incubation of both TBP and SUA7 together, however, results in the formation of a TBPSUA7-DNA complex (lane 3). There is a twofold decrease in the abundance of the ternary complex when $\mathrm{ADI}$ is added (cf. lanes 3 and 4). This decrease is not ATP dependent (lanes 4,5). Quantitation of the free DNA indicates that the decrease in the abundance of the ternary complex by ADI in the absence of ATP is not the result of the displacement of TBP and SUA7; rather, components of the ADI fraction supershift a small fraction of the TBP-SUA7-DNA complexes to new positions that are detected on longer exposure of the gel (not shown). The nature of such supershifted complexes has not been investigated further. Like TFIIA, SUA7 can also reverse the effect of ADI. When TBP-DNA complexes are first formed and then dissociated by the addition of ATP and $\mathrm{ADI}$, the subsequent addition of SUA7 results in the same level of TBP-SUA7-DNA complexes as are formed when ADI, ATP, and SUA7 are added to TBP and DNA together (cf. lanes 5 and 6).

Similar gel shift experiments were performed with human TFIIA and recombinant human TFIIB (data not shown). The results obtained with the human and yeast factors are nearly identical, with the exception that human TFIIB is less able than yeast TFIIB to protect TBP from $\mathrm{ADI}$ action.

\section{ADI action requires DNA $5^{\prime}$ to the TATA sequence}

As ADI is specific for TBP-DNA complexes, perhaps a certain region of promoter DNA is required to mediate the dissociation reaction. Further insight into the mechanism of action of ADI was obtained by determining which regions of DNA are essential for inhibitor action. This was accomplished by performing the gel shift analysis using fragments of DNA encompassing various regions of the major late promoter. As shown in Figure 5, $A$ and $B$, sequences $3^{\prime}$ to the boundary of the TBP footprint are dispensable for ADI action. Surprisingly, however, deletion of sequences $5^{\prime}$ to the footprint boundary (fragments $d$ and e) result in complexes not dissociated by $\mathrm{ADI}$. This suggests that ADI approaches a TBP-DNA

A
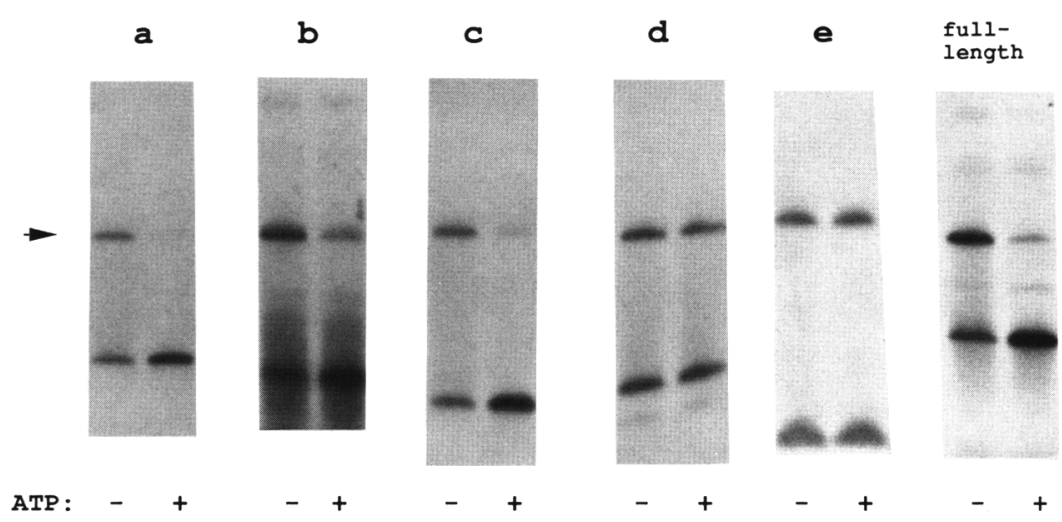

B

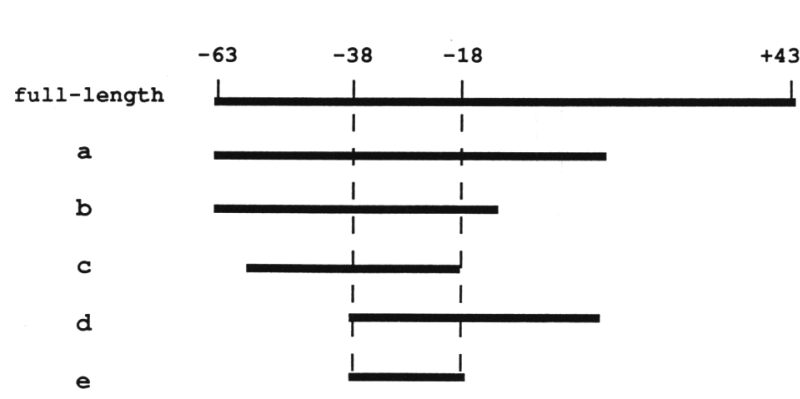

Figure 5. ADI activity requires DNA sequences $5^{\prime}$ to the TBP binding site. $(A)$ TBP was incubated with various radiolabeled adenovirus major late promoter DNA fragments $(a-e)$ in the presence of the ADI fraction and ATP where indicated. The approximate positions of the TBP-DNA complexes are shown by the arrow. The relationships of the various DNA fragments to each other and a summary of the data in $A$ are shown in $B$. The broken vertical lines at -38 and -18 indicate the approximate size of the TBP footprint. Note that fragments $d$ and $e$ which do not contain DNA $5^{\prime}$ to the TBP. protected footprint, fail to allow ADI to function. 
complex in a stereospecific manner that involves recognition or interaction with a particular surface of TBP and DNA.

\section{ADI interacts with the basic region of TBP}

In binding reactions containing TBP, TFIIA, and ADI, a competition results between TFIIA and ADI for mutually exclusive interaction with TBP (Fig. 4A; data not shown). This competitive behavior suggests that ADI and TFIIA might interact with a similar region of TBP. The conserved region of TBP consists of two 66- to 67amino-acid direct repeats that are separated by a region rich in basic amino acids. Previously, it has been shown that the direct repeats contribute to DNA binding, whereas the basic region interacts with TFIIA (Reddy and Hahn 1991; Buratowski and Zhou 1992; Yamamoto et al. 1992). To better define the interaction of TBP and ADI, two mutant TBPs were tested that each contain two amino acid changes in the basic region (Buratowski and Zhou 1992). Each of these mutants has been shown to be defective in interaction with TFIIA (Buratowski and Zhou 1992). As shown in Figure 6, the wild-type TBP forms TBP-ADI-DNA complexes in the absence of ATP, and the complexes are disrupted when ATP is added. (The TBP-ADI-DNA complex is a doublet in this experiment; we believe that certain preparations of ADI generate this doublet because ADI has been partially proteolyzed while still retaining its enzymatic activity.) The basic region mutants (K133,138L and $\mathrm{K} 133,145 \mathrm{~L}$ ) bind DNA but are defective in formation of the TBP-ADIDNA complex. ATP has little effect on the TBP-DNA

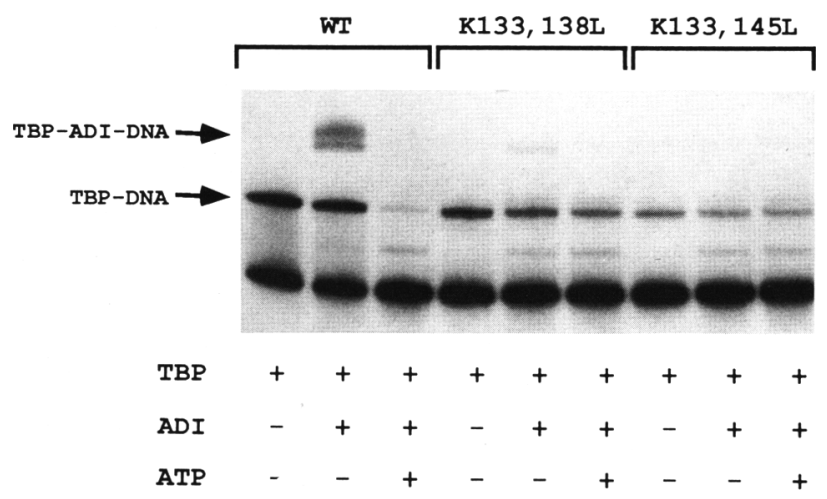

Figure 6. Amino acids in the basic region of TBP are involved in ADI recognition. Gel shift reactions were performed using the major late promoter and either wild-type TBP (WT) or recombinant TBP containing double amino acid changes in the basic region (K133,138L and K133,145L; Buratowski and Zhou 1992). TBP and DNA were incubated together for $20 \mathrm{~min}$ at room temperature, followed by the addition of $\mathrm{ADI}$ (2-3 units of the Bio-Rex 70 fraction; see Table 1 l and ATP where indicated. Reactions were analyzed on a nondenaturing polyacrylamide gel as described in Materials and methods. Note that wild-type TBP forms TBP-ADI-DNA complexes in the absence of ATP $\{\mathrm{a}$ doublet; see text) and that the wild-type TBP complexes are disrupted in the presence of ATP. In contrast, there is almost no effect of $\mathrm{ADI}$ on the basic region mutants. complexes formed with these proteins. The fact that the basic region mutants are defective in formation of the supershifted complex, as well as dissociation by ATP, provides additional support for the contention that the supershifted complex is composed of TBP, DNA, and ADI. Quantitation of the gel shows that $\mathrm{K} 133,138 \mathrm{~L}$ forms $<1 \%$ of the TBP-ADI-DNA complex formed by wild-type TBP, and TBP-ADI-DNA complexes are not detectable using $\mathrm{K} 133,145 \mathrm{~L}$. ADI plus ATP results in a 30-fold decrease in the abundance of the wild-type TBPDNA complex, whereas the complex with $\mathrm{K} 133,138 \mathrm{~L}$ is reduced 1.6-fold and the complex with $\mathrm{K} 133,145 \mathrm{~L}$ is not altered detectably. As with TFIIA, the interaction between TBP and ADI is mediated, at least in part, by interactions with the basic region of TBP.

\section{An inhibitor of transcription in vitro}

The effect of ADI on transcription was addressed by performing template commitment experiments using yeast TBP and general transcription factors obtained from HeLa cells (Samuels et al. 1982). Our fractionated yeast transcription system (Ranish et al. 1992) contains small amounts of TBP in several required fractions, so the HeLa system was used because of the well-characterized dependence on exogenously added TBP (Buratowski et al. 1988). The experiments employed the adenovirus major late promoter fused to each of two G-less cassettes of different lengths. Following transcription in the absence of GTP and treatment by RNase Tl, the two constructs yield transcripts of different lengths (Sawadogo and Roeder 1985a; Buratowski et al. 1988). The protocol for the experiments is shown in Figure $7 \mathrm{C}$, and the results are displayed in Figure 7, A and B. Note that transcription using both templates in the preincubation step yields comparable amounts of RNA from each plasmid (Figure 7A, lane 1). A limiting amount of yeast TBP was first incubated with template 1 for $25 \mathrm{~min}$, and then ADI was added either in the presence or absence of ATP, TFIIA, or TFIIB. Following a second incubation, the second template, the other general factors, RNA polymerase II, and nucleoside triphosphates were added. RNA synthesis was then allowed to proceed for $60 \mathrm{~min}$, the reactions were terminated, and the RNA products were resolved on polyacrylamide gels. The experiment in Figure 7A was performed with a low level of $\mathrm{ADI} / \sim 0.3$ units of activity; see Materials and methods). Lane 2 demonstrates that preincubation of template 1 with TBP results in almost exclusive transcription from this template and very little from the challenging template 2 . The differential transcription of the two templates is unaffected by the addition of ADI (lane 3). The addition of ADI plus ATP, however, leads to an overall decrease in transcription (by about twofold; lane 4), and transcription occurs from both templates. The addition of TFIIA (lane 5) blocks ADI action, and transcription occurs primarily from template 1. Human TFIIB also restores transcription to the same level as that obtained in the absence of ATP, but ADI has dissociated some of the TBP from template 1 allowing for increased transcription of tem- 
A

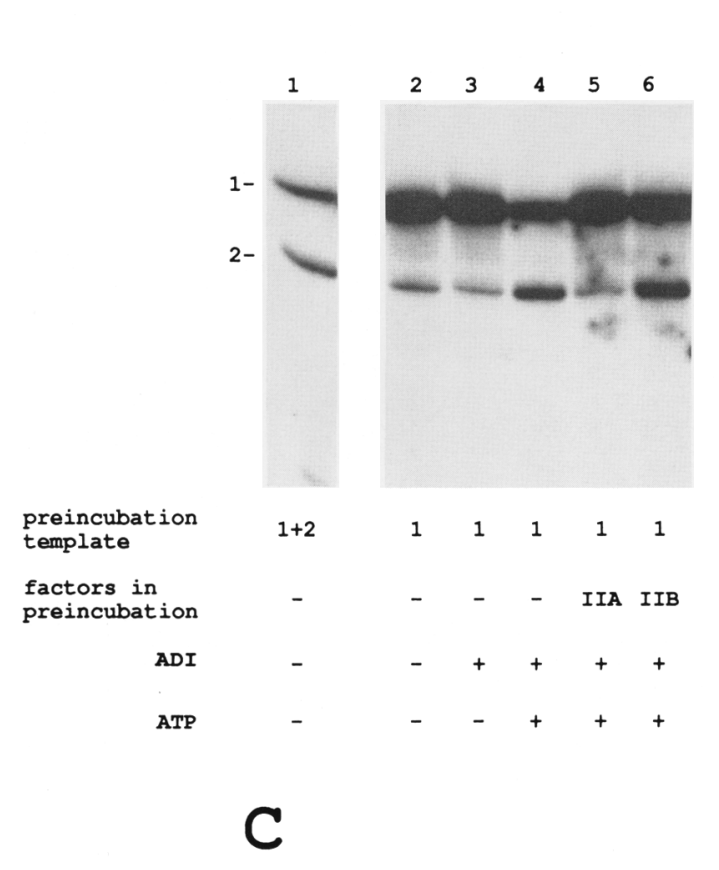

\section{B}

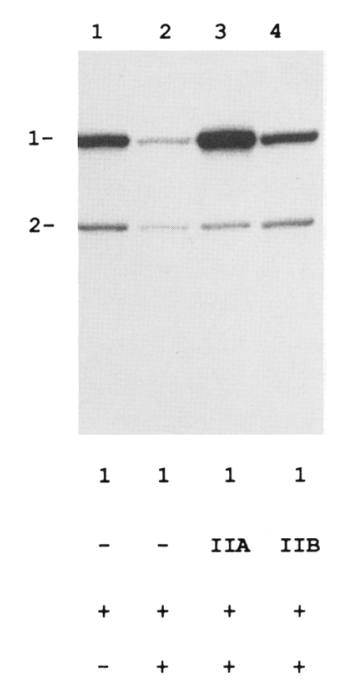

Figure 7. ADI affects template commitment and represses transcription in vitro in an ATP dependent manner. In vitro transcription reactions were performed using recombinant yeast TBP, human general transcription factors, and calf thymus RNA polymerase II as described in Materials and methods. Transcription from each of the two promoters employed can be distinguished because the templates contain different length G-less cassettes (Buratowski et al. 1988). (A) Transcription using an equimolar amount of each of the two templates generates very similar levels of RNA from each template (lane 1), whereas preincubation of template 1 with a limiting amount of TBP results primarily in transcription from template 1 (lane 2). TBP alone is also able to commit template 1 to transcription in the presence of TBP and ADI (lane 3), but when ATP is added (lane 4) the overall level of transcription is reduced (by about twofold) and transcription occurs from both templates. The ATP dependent inhibitory effect can be blocked by TFIIA (lane 5 ), and to a small but reproducible extent by human TFIIB (lane 6). $(B)$ In vitro transcription was performed essentially as in $A$, except that approximately three- to fourfold more ADI $(-1$ unit; see Table 1) was used in each reaction. Note that the addition of this increased amount of ADI plus ATP reduces transcription from both templates / cf. lane 1 with lane 2), and the effect is at least partially blocked by TFIIA and TFIIB (lanes 3,4). $(C)$ The protocol for the experiments shown in $A$ and $B$ is diagramed.

plate 2 (lane 6). The total level of transcription is the same $( \pm 3 \%)$ in lanes 5 and 6 , but TFIIA is more effective in committing a template to transcription in the presence of ADI and ATP.

The results of transcription experiments performed in the presence of higher levels of ADI ( 1 unit of activity) are shown in Figure 7B. The addition of ADI during the second preincubation results in an overall inhibition of transcription from both templates in an ATP dependent fashion (cf. lanes 1 and 2). As was found in the previous experiment, the inhibitory effect can be blocked by preincubation with TFIIA; and again, TFIIB has some protective effect but TFIIB does not function as well as TFIIA in blocking ADI action. These results are consistent with the behavior of ADI observed in the gel shift and footprinting assays.

\section{Discussion}

\section{Mechanism of action of ADI}

An activity in yeast nuclear extracts has been identified that specifically inhibits the binding of yeast TBP to
DNA. This activity requires micromolar concentrations of ATP and acts to rapidly remove TBP from its cognate DNA-binding site. ADI does not bind DNA alone as judged by gel shift analysis and DNase footprinting (Figure $1 \mathrm{~A}, \mathrm{~B} \mid$, nor does it appear to strongly bind full-length TBP in solution as measured by TBP affinity column chromatography (not shown). ADI can bind to a TBPDNA complex formed on either the major late promoter or the LEU2 promoter, although it has an apparently higher affinity for a TBP-DNA complex formed on the LEU2 promoter. Regardless of the DNA template used, ADI binds more tightly to $\triangle T B P-D N A$ complexes than to complexes formed with full-length TBP. The specificity of ADI for TBP is demonstrated by its failure to dissociate other protein-DNA complexes and its failure to dissociate basic region mutant TBP--DNA complexes. We have not detected either phosphorylation or adenylation of TBP, or TBP-dependent, covalent modification of proteins in the ADI fraction.

One model of ADI action that is consistent with all of the data is that $\mathrm{ADI}$ is an ATPase that utilizes the energy of ATP hydrolysis to dissociate TBP from DNA. Complexes containing TFIIA are stable so TBP is sequestered 
from the action of ADI (Fig. 8). TFIIB also has some ability to prevent dissociation of TBP from DNA by ADI, but the effects of TFIIB in either gel shift assays or transcription are less dramatic than that observed with TFIIA. It is possible that any protein that can form a complex with TBP and stabilize its binding to DNA will antagonize ADI action; the effectiveness of a factor in blocking ADI action could reflect the rate at which the factor binds a TBP-DNA complex and the stability of the ternary complex once it is formed. Because ADI does not tightly associate with wild-type TBP off the DNA, following the ATP dependent dissociation of a TBP-DNA complex the ADI molecule would be free to dissociate another TBPDNA complex and the dissociated TBP would be free to rebind DNA. Rebinding of DNA by a displaced TBP can explain why TFIIA added after ADI and ATP can form a TBP-TFIIA-DNA complex (Fig. 4A, lane 7). An ATPase activity has been detected in the ADI fraction (not shown), but its direct association with ADI will not be possible until the ADI has been purified to homogeneity.

The effects of TFIIA and TFIIB in countering the action of ADI are probably either attributable to a steric block of a surface of TBP recognized by ADI or to stabilization of TBP binding. The binding of TFIIA to a TBP-DNA complex protects DNA sequences $5^{\prime}$ to the TBP footprint, and DNA $5^{\prime}$ to the TBP binding site was shown to be essential for ADI action. Consistent with these results, DNase footprinting also showed that ADI protected two positions from DNase I digestion just upstream from the $5^{\prime}$ boundary of the TBP footprint. Because the DNA sequences of the promoters that were employed in the ADI assay do not contain conserved DNA sequences $5^{\prime}$ to the TBP footprint, it is possible that ADI makes nonspecific contacts with the DNA in this region, and these contacts may serve to either orient the inhibitor or to provide a "grip" with which TBP can be dissociated from the TATA sequence. However, ADI appears to bind more tightly to a TBP-DNA complex formed on the LEU2 promoter than on the major late promoter or any of the other promoters tested (not shown) so base-specific contacts may contribute to the affinity of ADI for a particular TBP-DNA complex. The

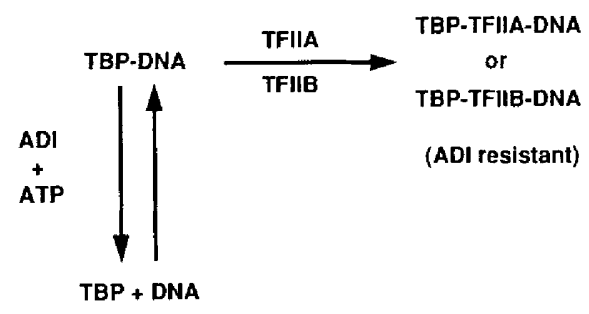

Figure 8. Model of ADI action. A summary of the effects of ADI on complexes formed between DNA and TBP and TFIIA and TFIIB is shown. ADI can dissociate TBP-DNA complexes in an ATP dependent reaction. It is hypothesized that the dissociated TBP and DNA can then rebind and undergo another round of dissociation by ADI. However, the association of TFIIA or TFIIB with the TBP-DNA complex generates complexes that are protected from ADI action. binding of TBP to DNA involves interaction with the minor groove (Lee et al. 1991; Starr and Hawley 1991). The specificity of ADI action may be conferred in part by this unusual mode of binding.

\section{Other inhibitors of transcription complex assembly}

Roeder and co-workers have described two activities from human cells that interact with human TBP. These two factors, termed $\mathrm{NCl}$ (Meisterernst et al. 1991) and NC2 (Meisterernst and Roeder 1991), form complexes with recombinant human TBP in gel shift assays and they inhibit the association of TFIIA and TFIIB with TBP. These two activities also inhibit basal transcription in vitro and are thought to be important in transcriptional activation by the activator proteins $\mathrm{Spl}$ and USF. The inhibitor that we describe is likely different from $\mathrm{NCl}$ and $\mathrm{NC} 2$ because $\mathrm{NC1}$ and $\mathrm{NC} 2$ have not been shown to dissociate TBP from DNA and they have no known ATP requirement for their activity.

Additional work has demonstrated the existence of two inhibitory activities in extracts from human cells termed Drl and Dr2 (Inostroza et al. 1992). Drl is an inhibitor of both basal and activated transcription, and this activity has been purified and the gene encoding it has been cloned (Inostroza et al. 1992). Like NC1 and $\mathrm{NC2}$, Drl is a mammalian TBP-associated protein. Dr2 is an inhibitor of basal transcription. The Drl polypeptide is $19 \mathrm{kD}$ (Inostroza et al. 1992) with a native mass of $\sim 90 \mathrm{kD}$, whereas ADI has a molecular mass of $>150 \mathrm{kD}$ by gel filtration, and no small polypeptides correlate with ADI activity as it elutes from ion exchange columns (not shown). Also, unlike ADI, the action of Drl is not blocked by TFIIA (Inostroza et al. 1992). As Drl and Dr2 have not been described to possess any ATP dependent activity, it appears that ADI is distinct from $\mathrm{Dr} 1$ and Dr2.

It has been reported that TFIIA is required for mammalian in vitro transcription employing the TFIID fraction but not purified TBP (Cortes et al. 1992). Because the mammalian TBP has been shown to be tightly associated with a number of other polypeptides (Tanese et al. 1991\}, this result has been interpreted to indicate that TFIIA may be an antirepressor whose function is to counteract the activity of an inhibitor associated with TBP (Cortes et al. 1992). Similarly, yeast TFIIA may activate transcription, at least in part, by functioning as an antirepressor that counteracts ADI.

\section{Possible roles of $A D I$}

In light of the data presented in this study, several possible functions of ADI can be imagined. First, ADI may be involved in maintaining promoter specificity. It has been shown that TBP will bind to multiple, diverse DNA sequences with comparable affinity (Hahn et al. $1989 \mathrm{c}$; Singer et al. 1990). While other sequences [e.g., unstream activating sequences (UASs)] help to determine which TBP-binding sites are ultimately utilized as promoters, 
the stable binding of TBP to DNA may necessitate an activity that is capable of dissociating TBP from TATAlike sequences located throughout the genome at nonpromoter sites. It is surprising that yeast cells are not affected by the 20 -fold overexpression of wild-type TBP (Reddy and Hahn 1991), a situation that might be expected to drive the binding of TBP to DNA and inappropriately activate transcription. Perhaps this inappropriate TBP binding is prevented by ADI. It is also possible that ADI regulates transcription in vivo at only a subset of promoters. The selective requirement of certain general transcription factors (i.e., TFIIA and TFIIB) and/or the rate at which they assemble with TBP could influence the degree to which ADI effects transcription initiation at specific promoters. Finally, TBP is also required for the transcription of genes transcribed by RNA polymerases I and III (Dahlberg and Lund 1991; Comai et al. 1992; Cormack and Struhl 1992; Schultz et al. 1992; White et al. 1992), and ADI may be involved in the regulation of genes transcribed by either of the other polymerases. Because ADI action is blocked by other factors that interact with TBP, it is less likely that TBP complexes formed on other promoters that do not contain TATA boxes would be affected by ADI. ADI may play a role, however, in regulating transcription from genes transcribed by RNA polymerase III that contain a TATA box (such as the U6 gene; Dahlberg and Lund 1991). In view of the high degree of conservation of the components of the RNA polymerase II transcription apparatus that have been described thus far, and the ability of ADI to function in conjunction with human factors, it is possible that similar inhibitor activities exist in other eukaryotic cells as well.

\section{Materials and methods}

\section{Gel shift assay of ADI activity}

Radiolabeled DNA fragment $(0.5 \mathrm{nM}, 20,000 \mathrm{cpm} / \mathrm{ng}$; see below) was incubated at room temperature for $30 \mathrm{~min}$ with $10 \mathrm{nM}$ recombinant yeast TBP (either full-length or truncated TBP) in a $20-\mu l$ binding reaction that contained $4 \mathrm{mM}$ Tris- $\mathrm{Cl}(\mathrm{pH} 8), 60$ $\mathrm{mm} \mathrm{KCl}, 5 \mathrm{mM} \mathrm{MgCl}, 4 \%$ glycerol, $0.1 \%$ Brij $58,100 \mathrm{ng}$ of poly [dG-dC] and $100 \mu \mathrm{g} / \mathrm{ml}$ of BSA. One unit $(\sim 1 \mu \mathrm{l})$ of ADI activity from the Bio-Rex fraction (see Table 1) and/or $5 \mu \mathrm{M}$ ATP were included where indicated. The reaction products were analyzed on $6 \%$ polyacrylamide gels containing $25 \mathrm{~mm}$ Tris $(\mathrm{pH} 8.3), 190$ $\mathrm{mm}$ glycine, $5 \mathrm{~mm}$ magnesium acetate, $2.5 \%$ (vol/vol) glycerol and $0.5 \mathrm{~mm}$ DTT in running buffer containing $25 \mathrm{mM}$ Tris $\mid \mathrm{pH}$ 8.3), $190 \mathrm{~mm}$ glycine, and $5 \mathrm{~mm}$ magnesium acetate. Gels were run at $4^{\circ} \mathrm{C}$. Binding reactions containing TFIIA and/or TFIIB were performed under the same conditions as for TBP alone. Complexes containing TFIIB were detected on gels as described above but that lacked glycerol and magnesium acetate and were run at room temperature in Tris-glycine buffer lacking magnesium acetate (Buratowski et al. 1991). These are the only conditions we have found that allow the detection of complexes containing TFIIB in a gel shift assay. Quantitation of the levels of gel-shifted complexes was performed by either densitometry or PhosphorImager analysis.

The binding of GAL4-VP16 to DNA occurred under the same conditions as for TBP, but the reaction products were analyzed on $6 \%$ polyacrylamide gels in Tris-glycine buffer without magnesium acetate or DTT. HAP2,3,4 protein was also bound to DNA in the same buffer as TBP, but the reaction products were analyzed on $6 \%$ polyacrylamide gels that were run in $10 \mathrm{~mm}$ Tris-Cl (pH 8), 1 mM EDTA.

\section{DNA fragments}

Most of the binding reactions contained a radiolabeled 106-bp EcoRI-XbaI fragment from plasmid pRW2 (Chodosh et al. 1986). This fragment contains adenovinus major late promoter sequences from -50 to +33 . The binding of TBP to the LEU2 TATA sequence utilized a radiolabeled 59-bp Sall-AvaI fragment from pMS1 (Hahn et al. 1989b).

HAP $2,3,4$ protein was bound to a radiolabeled 89 -bp SmaIXhoI fragment from p265up-1, which contains the HAP2,3,4 UAS2up-1-binding site (Hahn and Guarente 1988). The binding of GAL4-VP16 to DNA was detected using a radiolabeled 107bp XhoI-SacI fragment from pSK Gal4, which contains a single copy of a GAL4-binding site (Chasman et al. 1989) cloned into the EcoRI and BamHI sites of pSK II. Adenovinus major late promoter fragments of 72 and $51 \mathrm{bp}$ in length (fragments a and $\mathrm{b}$ in Fig. 5/ were obtained by digestion of pRW2 with $\mathrm{XbaI}$ and Earl $(72 \mathrm{bp}$ ) or $\mathrm{XbaI}$ and $\mathrm{HhaI}(51 \mathrm{bp})$, followed by labeling at the $X b a I$ site with the Klenow fragment of DNA polymerase and $\left[\alpha^{-32} \mathrm{P}\right] \mathrm{dCTP}$. The 39-bp fragment c (Fig. 5) was obtained by polymerase chain reaction using 20 -base oligonucleotides complementary to the major late promoter sequence. Fragment $d$ is 45 $\mathrm{bp}$ in length and $\mathrm{e}$ is $20 \mathrm{bp}$; both of these fragments were obtained by chemical synthesis of DNA.

\section{Footprinting of TBP bound to DNA}

The binding conditions were similar to those described above for the gel shift assay except that the DNA concentration was 5 $\mathrm{nM}, \mathrm{TBP}$ was present at $48 \mathrm{nM}$ and reactions contained 6.5 units of ADI activity where indicated. The DNA template consisted of the 106-bp EcoRI-XbaI major late promoter fragment uniquely labeled at the $X b a$ I site. Following a 30-min incubation at room temperature, $5 \mathrm{ng}$ of DNase I was added for 15-40 sec. The reactions were terminated by ethanol precipitation, and the reaction products were analyzed on $10 \%$ polyacrylamide-urea sequencing gels.

\section{Recombinant proteins}

TBP was purified from an $E$. coli strain overproducing TBP under control of the phage $\mathrm{T} 7$ promoter as described previously (Reddy and Hahn 1991). Truncated TBP ( $\triangle T B P$ ) consists of TBP that has been digested proteolytically to remove the aminoterminal 55 amino acids and then purified further to eliminate the cleaved amino-terminal peptide. The truncated protein was the generous gift of J. Geiger (Yale University, New Haven, CT). The TBP preparations used in these studies had no detectable contaminants, as judged by silver staining of SDS-polyacrylamide gels. Plasmids encoding the TBP basic region mutants $\mathrm{K} 133,138 \mathrm{~L}$ and $\mathrm{K} 133,145 \mathrm{~L}$ under control of the $\mathrm{T} 7$ promoter were obtained from S. Buratowski |Whitehead Institute, Cambridge, $\mathrm{MA}$, and the proteins were purified from an $E$. colioverproducing strain as described (Buratowski and Zhou 1992). TFIIA was purified from E. coli as described (Ranish et al. 1992).

GAL4-VP16 fusion protein was purified from an E. coli strain overproducing GAL4-VP16 under control of the tac promoter as 
described (Chasman et al. 1989). The HAP2,3,4 complex was purified from yeast as described (Hahn and Guarente 1988).

Recombinant SUA7 (yeast TFIIB; $>90 \%$ pure) was purified by chromatography on Bio-Rex 70 and DEAE from an E. coli-overproducing strain provided by E. Maldonado and D. Reinberg (RWJ Medical School, Piscataway, NI).

\section{Purification of $A D I$}

Yeast nuclear extracts were prepared from 370 grams of strain BJ5626 (Jones 1991) essentially as described (Ranish and Hahn 1991). Protein (637 mg; $87 \%$ of the extract) was adjusted so that the conductivity equaled that of TA $130 \mathrm{~mm}$ Tris-acetate at $\mathrm{pH}$ $8,2 \mathrm{mM}$ EDTA, $10 \%$ glycerol, $1 \mathrm{mM} \mathrm{DTT}, 0.16 \mathrm{mg} / \mathrm{ml}$ of PMSF, $1.4 \mathrm{mg} / \mathrm{ml}$ of pepstatin, $2 \mathrm{mg} / \mathrm{ml}$ of chymostatin, $0.3 \mathrm{mg} / \mathrm{ml}$ of leupeptin, $2 \mathrm{~mm}$ benzamidine) plus $50 \mathrm{~mm}$ ammonium sulfate. The extract was then batch loaded to $35 \mathrm{ml}$ of DEAE-Sepharose equilibrated in TA $+50 \mathrm{~mm}$ ammonium sulfate by incubating at $4^{\circ} \mathrm{C}$ with rocking for $60 \mathrm{~min}$. The extract/DEAE mix was then loaded to a column and washed with $70 \mathrm{ml}$ of TA $+50 \mathrm{~mm}$ ammonium sulfate. ADI could not be assayed at this stage of the purification, but it was known to flow through DEAE from previous work (not shown). The conductivity of $88 \%$ (168 mg) of the DEAE flowthrough was adjusted with $3 \mathrm{M}$ ammonium sulfate to that of buffer A (10 mM Tris-Cl at pH 8,2 mM EDTA, $10 \%$ glycerol, $1 \mathrm{mM} \mathrm{DTT}$, with the protease inhibitors as in TA) plus $1.3 \mathrm{M}$ ammonium sulfate, and the protein was batch loaded to $15 \mathrm{ml}$ of phenyl-Sepharose equilibrated in buffer A by rocking at $4^{\circ} \mathrm{C}$ for $45 \mathrm{~min}$. The protein/phenyl-Sepharose mix was poured into a column and washed with $50 \mathrm{ml}$ of $\mathrm{A}+0.77 \mathrm{M}$ ammonium sulfate. Protein was then eluted in a $40-\mathrm{ml}$ decreasing linear gradient of ammonium sulfate from $0.77 \mathrm{M}$ to zero ammonium sulfate. Inhibitory activity was detected by assaying dialyzed column fractions across the gradient in the gel shift assay described above. ADI was assayed again by gel shift assay and found to elute from $\sim 0.54-0.11 \mathrm{M}$ ammonium sulfate. The active fractions were pooled and dialyzed such that the conductivity equaled that of $\mathrm{HA}$ / $30 \mathrm{~mm}$ HEPES at $\mathrm{pH} 8,2$ mM EDTA, $10 \%$ glycerol, $1 \mathrm{mM} \mathrm{DTT}$, and the protease inhibitors as in TA) plus $0.1 \mathrm{M}$ potassium acetate. A percentage $(15.6 \mathrm{mg})$ of this pooled protein $(98 \%$ ) was then loaded onto a $4.5-\mathrm{ml}$ Bio-Rex 70 column equilibrated in $\mathrm{HA}+0.1 \mathrm{~m}$ potassium acetate. The column was washed with $12 \mathrm{ml}$ of loading buffer and then protein eluted with a $50-\mathrm{ml}$ linear gradient from 0.1 to $0.7 \mathrm{M}$ potassium acetate. ADI eluted from $\sim 0.47$ to $0.55 \mathrm{~mm}$ potassium acetate. The inhibitor activity purified through the Bio-Rex 70 fractionation step is estimated to be enriched from yeast cells $\sim 1000$ fold.

\section{In vitro transcription}

The in vitro transcription reactions utilized recombinant yeast TBP $(2.8 \mathrm{ng} /$ reaction), human TFIIA (fraction $\mathrm{AB}$ ), and other HeLa cell general transcription factors (fraction $C B$ ) isolated as described (Samuels et al. 1982) and kindly provided by S. Buratowski. RNA polymerase II was purified from calf thymus as described (Samuels et al. 1982). The DNA templates (50 ng/ reaction) consisted of the adenovirus major late promoter fused to G-less cassettes of different lengths, and transcription was performed essentially as described (Buratowski et al. 1988) ex cept for the order in which the components were added and the lengths of the various preincubations that are depicted in Figure 7C. The reactions were performed in the presence of $\left[\alpha^{-32} \mathrm{P}\right] \mathrm{CTP}$, and the products were analyzed by autoradiography of $6 \%$ poly- acrylamide-urea gels. Quantitation of the transcript levels was performed by either densitometry or PhosphorImager analysis.

\section{Acknowledgments}

We are grateful to Jim Geiger for the gift of $\triangle T B P ; E$. Maldonado and D. Reinberg for the E. coli strain that overproduces SUA7; F. Pugh and R. Tiian for recombinant human TFIIB; and S. Buratowski for the plasmids containing TBP basic region mutations. We thank Phil Sharp for suggesting that ATP might improve the binding of TBP to DNA; and Danny Reinberg, Mark Groudine, Jeff Ranish and Trent Colbert for comments on the manuscript. This work was supported by a grant from the $\mathrm{Na}$ tional Institutes of Health and an American Cancer Society Junior Faculty Award to S.H. D.T.A. was supported in part by a cancer research fellowship from the Ladies Auxiliary to the V.F.W.

The publication costs of this article were defrayed in part by payment of page charges. This article must therefore be hereby marked "advertisement" in accordance with 18 USC section 1734 solely to indicate this fact.

\section{References}

Abmayr, S.M., J.L. Workman, and R.G. Roeder. 1988. The pseudorabies immediate early protein stimulates in vitro transcription by facilitating TFIID : promoter interactions. Genes \& Dev. 2: 542-553.

Buratowski, S. and H. Zhou. 1992. TFIID mutants defective for interaction with TFIIA. Science 255: 1130-1132.

Buratowski, S., S. Hahn, P.A. Sharp, and L. Guarente. 1988. Function of a yeast TATA element-binding protein in a mammalian transcription system. Nature 334: 37-42.

Buratowski, S., S. Hahn, L. Guarente, and P.A. Sharp. 1989. Five intermediate complexes in transcription initiation by RNA polymerase II. Cell 56: 549-561.

Buratowski, S., M. Sopta, J. Greenblatt, and P.A. Sharp. 1991. RNA polymerase II-associated proteins are required for a DNA conformation change in the transcription initiation complex. Proc. Nat1. Acad. Sci. 88: 7509-7513.

Carey, M., J. Leatherwood, and M. Ptashne. 1990. A potent GAL4 derivative activates transcription at a distance in vitro. Science 247: 710-712.

Chasman, D.I., J. Leatherwood, M. Carey, M. Ptashne, and R.D. Kornberg. 1989. Activation of yeast polymerase II transcription by herpesvirus VP16 and GAL4 derivatives in vitro. Mol. Cell. Biol. 9: 4746-4749.

Chodosh, L.A., R.W. Carthew, and P.A. Sharp. 1986. A single polypeptide possesses the binding and transcription activities of the adenovirus major late transcription factor. Mol. Cell. Biol. 6: 4723-4733.

Comai, L., N. Tanese, and R. Tjian. 1992. The TATA-binding protein and associated factors are integral components of the RNA polymerase I transcription factor, SL1. Cell 68: 965976.

Cormack, B.P. and K. Struhl. 1992. The TATA-binding protein is required for transcription by all three nuclear RNA polymerases in yeast cells. Cell 69: 685-696.

Cormack, B.P., M. Strubin, A.S. Ponticelli, and K. Struhl. 1991. Functional differences between yeast and human TFIID are localized to the highly conserved region. Cell 65: 341-348.

Cortes, P., O. Flores, and D. Reinberg. 1992. Factors involved in specific transcription by mammalian RNA polymerase II: Purification and analysis of transcription factor IIA and iden- 
tification of transcription factor IIJ. Mol. Cell. Biol. 12: 413421.

Dahlberg, J.E. and E. Lund. 1991. How does III $\times$ II make U6? Science 254: 1462-1463.

Davison, B.L., J.-M. Egly, E.R. Mulvihill, and P. Chambon. 1983. Formation of stable preinitiation complexes between eukaryotic class B transcription factors and promoter sequences. Nature 301: 680-686.

Fischer, L., M. Gerard, C. Chalut, Y. Lutz, S. Humbert, M. Kanno, P. Chambon, and J.-M. Egly. 1992. Cloning of the 62-kilodalton component of basic transcription factor BTF2. Science 257: 1392-1395.

Forsburg, S.L. and L. Guarente. 1989. Identification and characterization of HAP4: A third component of the CCAATbound HAP2/HAP3 heteromer. Genes \& Dev. 3: 1166-1178.

Gileadi, O., W.J. Feaver, and R.D. Kornberg. 1992. Cloning of a subunit of yeast RNA polymerase II transcription factor b and CTD kinase. Science 257: 1389-1392.

Greenblatt, J. 1991. Roles of TFIID in transcriptional initiation by RNA polymerase II. Cell 66: 1067-1070.

Hahn, S. and L. Guarente. 1988. Yeast HAP2 and HAP3: Transcriptional activators in a heteromeric complex. Science 240: $317-321$.

Hahn, S., S. Buratowski, P.A. Sharp, and L. Guarente. 1989a. Identification of a yeast protein homologous in function to the mammalian general transcription factor, TFIIA. EMBO $\%$. 8: 3379-3382.

$1089 \mathrm{~b}$. Isolation of the gene encoding the yeast TATA binding protein TFIID: A gene identical to the SPT15 suppressor of Ty element insertions. Cell 58: 1173-1181.

- 1989c. Yeast TATA-binding protein TFIID binds to TATA elements with both consensus and nonconsensus DNA sequences. Proc. Natl. Acad. Sci. 86: 5718-5722.

Horikoshi, M., M.F. Carey, H. Kakidani, and R.G. Roeder. 1988a. Mechanism of action of a yeast activator: Direct effect of GAL4 derivatives on mammalian TF2D-promoter interaction. Cell 54: 665-669.

Horikoshi, M., T. Hai, Y.-S. Lin, M.R. Green, and R.G. Roeder. 1988b. Transcription factor ATF interacts with the TATA factor to facilitate establishment of a preinitiation complex. Cell 54: 1033-1042.

Horikoshi, N., K. Maguire, A. Kralli, E. Maldonado, D. Reinberg, and R. Weinman. 1991. Direct interaction between adenovirus E1A protein and the TATA box binding transcription factor IID. Proc. Natl. Acad. Sci. 88: 5124-5128.

Inostroza, J.A., F.H. Mermelstein, I.H. Ha, W.S. Lane, and D. Reinberg. 1992. Drl, a TATA-binding protein-associated phosphoprotein and inhibitor of class II transcription. Cell 70: $477-489$.

Jones, E.W. 1991. Tackling the protease problem in Saccharomyces cerevisiae. Methods Enzymol. 194: 428-453.

Lee, D.K., M. Horikoshi, and R.G. Roeder. 1991. Interaction of TFIID in the minor groove of the TATA element. Cell 67: $1241-1250$.

Lee, W.S., C.C. Kao, G.O. Bryant, X. Liu, and A.J. Berk. 1991. Adenovirus ElA activation domain binds the basic repeat in the TATA box transcription factor. Cell 67: 365-376.

Lin, Y.-S., I. Ha, E. Maldonado, D. Reinberg, and M. Green. 1991. Binding of general transcription factor TFIIB to an acidic activating region. Nature 353: $569-571$.

Lu, H., L. Zawel, L. Fisher, J.-M. Egly, and D. Reinberg. 1992. Human general transcription factor IIH phosphorylates the C-terminal domain of RNA polymerase II. Nature 358: 641645.

Lüscher, B., E. Christenson, D.W. Litchfield, E.G. Krebs, and R.N. Eisenman. 1990. Myb DNA binding inhibited by phos- phorylation at a site deleted during oncogenic activation. Nature 344: 517-522.

Maldonado, E., I. Ha, P. Cortes, L. Weis, and D. Reinberg. 1990. Factors involved in specific transcription by mammalian RNA polymerase II: Role of transcription factors IIA, IID, and IIB during formation of a transcription-competent complex. Mol. Cell. Biol. 10: 6335-6347.

Meisterernst, M. and R.G. Roeder. 1991. Family of proteins that interact with TFIID and regulate promoter activity. Cell 67: 557-567.

Meisterernst, M., A.L. Roy, H.M. Lieu, and R.G. Roeder. 1991. Activation of class II gene transcription by regulatory factors is potentiated by a novel activity. Cell 66: 981-993.

Nikolov, D.B., S.-H. Hu, J. Lin, A. Gasch, A. Hoffmann, M. Horikoshi, N.-H. Chua, R.G. Roeder, and S.K. Burley. 1992. Crystal structure of TFIID TATA-box binding protein. $\mathrm{Na}$ ture 360: $40-46$.

Pinto, I., D.E. Ware, and M. Hampsey. 1992. The yeast SUA7 gene encodes a homolog of human transcription factor TFIIB and is required for normal start site selection in vivo. Cell 68: $977-988$.

Pugh, B.F. and R. Tiian. 1990. Mechanism of transcriptional activation by $\mathrm{Sp1:}$ Evidence for coactivators. Cell 61: 11871197.

Ranish, J.A. and S. Hahn. 1991. The yeast general transcription factor TFIIA is composed of two polypeptide subunits. $I$. Biol. Chem. 266: 19320-19327.

Ranish, J.A., W.S. Lane, and S. Hahn. 1992. Isolation of two genes that encode subunits of the yeast transcription factor IIA. Science 255: 1127-1129.

Reddy, P. and S. Hahn. 1991. Dominant negative mutations in yeast TFIID define a bipartite DNA-binding region. Cell 65: 349-357.

Samuels, M., A. Fire, and P.A. Sharp. 1982. Separation and characterization of factors mediating accurate transcription by RNA polymerase II. I. Biol. Chem. 257: 14419-14427.

Sawadogo, M. and R.G. Roeder. 1985a. Factors involved in specific transcription by human RNA polymerase II: Analysis by a rapid and quantitative in vitro assay. Proc. Natl. Acad. Sci. 82: 4394-4398.

- 1985b. Interaction of a gene-specific transcription factor with the adenovirus major late promoter upstream of the TATA box region. Cell 43: 165-175.

Sawadogo, M. and A. Sentenac. 1990. RNA polymerase B (II) and general transcription factors. Annu. Rev. Biochem. 59: 711754.

Schultz, M.C., R.H. Reeder, and S. Hahan. 1992. Variants of the TATA-binding protein can distinguish subsets of RNA polymerase I, II, and III. Cell 69: 697-702.

Singer, V.L., C.R. Wobbe, and K. Struhl. 1990. A wide variety of DNA sequences can functionally replace a yeast TATA element for transcriptional activation. Genes \& Dev. 4: 636645 .

Starr, D.B. and D.K. Hawley. 1991. TFIID binds in the minor groove of the TATA box. Cell 67: 1231-1240.

Stringer, K.F., C.J. Ingles, and J. Greenblatt. 1990. Direct and selective binding of an acidic transcriptional activation domain to the TATA-box factor TFIID. Nature 345: 783-786.

Tanese, N., B.F. Pugh, and R. Tjian. 1991. Coactivators for a proline-rich activator purified from the multisubunit human TFIID complex. Genes \& Dev. 5: 2212-2224.

Van Dyke, M.W., R.G. Roeder, and M. Sawadogo. 1988. Physical analysis of transcription preinitiation complex assembly on a class II gene promoter. Science 241: 1335-1338.

White, R.J., S.P. Jackson, and P.W.J. Rigby. 1992. A role for the TATA-box-binding protein component of the transcription 
factor IID complex as a general RNA polymerase III transcription factor. Proc. Natl. Acad. Sci. 89: 1949-1953.

Yamamoto, T., M. Horikoshi, J. Wang, S. Hasegawa, P.A. Weil, and R. G. Roeder. 1992. A bipartite DNA-binding domain composed of direct repeats in the TATA box binding factor TFIID. Proc. Natl. Acad. Sci. 89: 2844-2848.

Zawel, L. and D. Reinberg. 1992. Advances in RNA polymerase II transcription. Curr. Opin. Cell Biol. 4: 488-495.

Zhou, Q., P.M. Lieberman, T.G. Boyer, and A.J. Berk. 1992. Holo-TFIID supports transcriptional stimulation by diverse activators and from a TATA-less promoter. Genes \& $\mathrm{Dev}$. 6: $1964-1974$. 


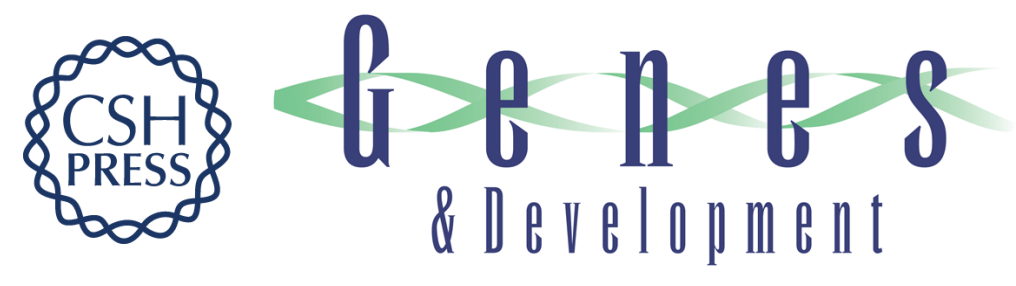

\section{An ATP-dependent inhibitor of TBP binding to DNA.}

D T Auble and S Hahn

Genes Dev. 1993, 7:

Access the most recent version at doi:10.1101/gad.7.5.844

References This article cites 55 articles, 25 of which can be accessed free at: http://genesdev.cshlp.org/content/7/5/844.full.html\#ref-list-1

\section{License}

Email Alerting

Receive free email alerts when new articles cite this article - sign up in the box at the Service top right corner of the article or click here.

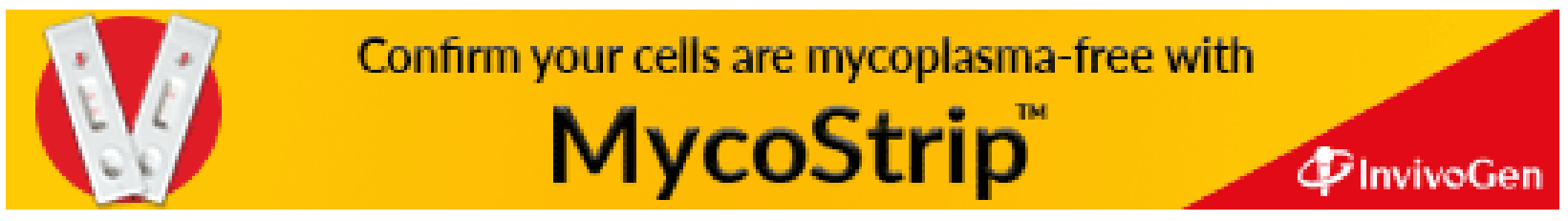

